\title{
LAS FRONTERAS BLANDAS \\ Una aproximación conceptual a la seguridad urbana desde la perspectiva del urbanismo
}

\author{
Autor: Camilo Osorio \\ Universidad o Institución a la que pertenece: Universidad Politécnica de Cataluña - Barcelona Tech \\ Director de la tesis en curso o de la investigación: Joaquín Sabaté \\ E-Mail: camilo.osorio.ar@gmail.com
}

\section{RESUMEN}

El espacio público como el escenario de la acción urbana colectiva, es el principal ámbito donde se pone de manifiesto la seguridad de una ciudad. De ahí que exista una estrecha correlación entre estos dos componentes: seguridad y espacio. Este último, si bien puede no ser el causante de una mayor o menor seguridad, sí que la facilita, o la inhibe. En este texto quisiéramos verificar hasta qué punto dicha seguridad del espacio público, depende de que éste sea poroso, integrado y mixto, o que favorezca una ocupación continuada.

Con base a una experiencia de más de 5 décadas de investigaciones sobre dicha relación, este artículo busca adentrarse desde una mirada transversal y actualizada sobre la seguridad urbana y en una aproximación marcadamente urbanística.

La seguridad provee bienestar social, y las que denomino Fronteras Blandas como garantes de porosidad, integración y mezcla urbana, dotan vida al espacio público y le confieren mayor urbanidad.

Palabras clave: seguridad urbana, porosidad, integración, mezcla social y de usos

\section{ABSTRACT}

Public space as the platform of urban collective action is the main realm where safety is manifested in a city. So that there is a close correlation between these two components: safety and space. The second one, although it may not be the cause of unsafety, it facilitates it, or it inhibits it. In this text we would like to verify to what extent this safety of public space depends on whether it is porous, integrated and mixed, or it favors a continuous occupation.

Based on an experience of over 5 decades of research on this relationship, this article seeks to look from a transversal and updated view on urban safety and in a markedly urbanistic approach.

Safety provides social welfare, and those I call 'Soft Borders' as guarantors of porosity, integration and urban mixing, endow public space with life and give it greater urbanity.

Key words: urban safety, porosity, integration, mixed-use/social mix 


\section{INTRODUCCIÓN: UN PROBLEMA MUNDIAL, UN ENFOQUE MUNDIAL}

Vivimos en un mundo crecientemente urbano. Hoy la mitad de la población mundial se concentra en ciudades, conglomerados de gente y de oportunidades, pero también de carencias. En 1950 sólo el 30\% de la población mundial era urbana, en 2050 será el 70\%, es decir, con una población cercana a los 10 mil millones de personas, en las ciudades se concentrarán 7 mil millones, toda la población mundial en la actualidad. En sólo en un siglo habremos pasado de ser un mundo rural a serlo urbano.

En América Latina el panorama no es diferente, si hoy ya cerca del 80\% de la población es urbana, en 2050 será el $90 \%$, casi su totalidad. Es allí donde toma forma el que en la actualidad resulta uno de los mayores problemas del imaginario colectivo: la inseguridad urbana, la presencia eterna del delito callejero como respuesta al conflicto que supone la ciudad como un conglomerado social mixto.

Según la Oficina de Naciones Unidas contra la Droga y el Delito, y de acuerdo con el número de homicidios por cada 100.000 habitantes, de los 12 países menos seguros del mundo, 10 están en Latinoamérica y el Caribe: Honduras, Venezuela, Belice, El Salvador, Guatemala, Jamaica, San Cristóbal y Nieves, Colombia, Las Bahamas y Trinidad y Tobago (Ver figura 1).

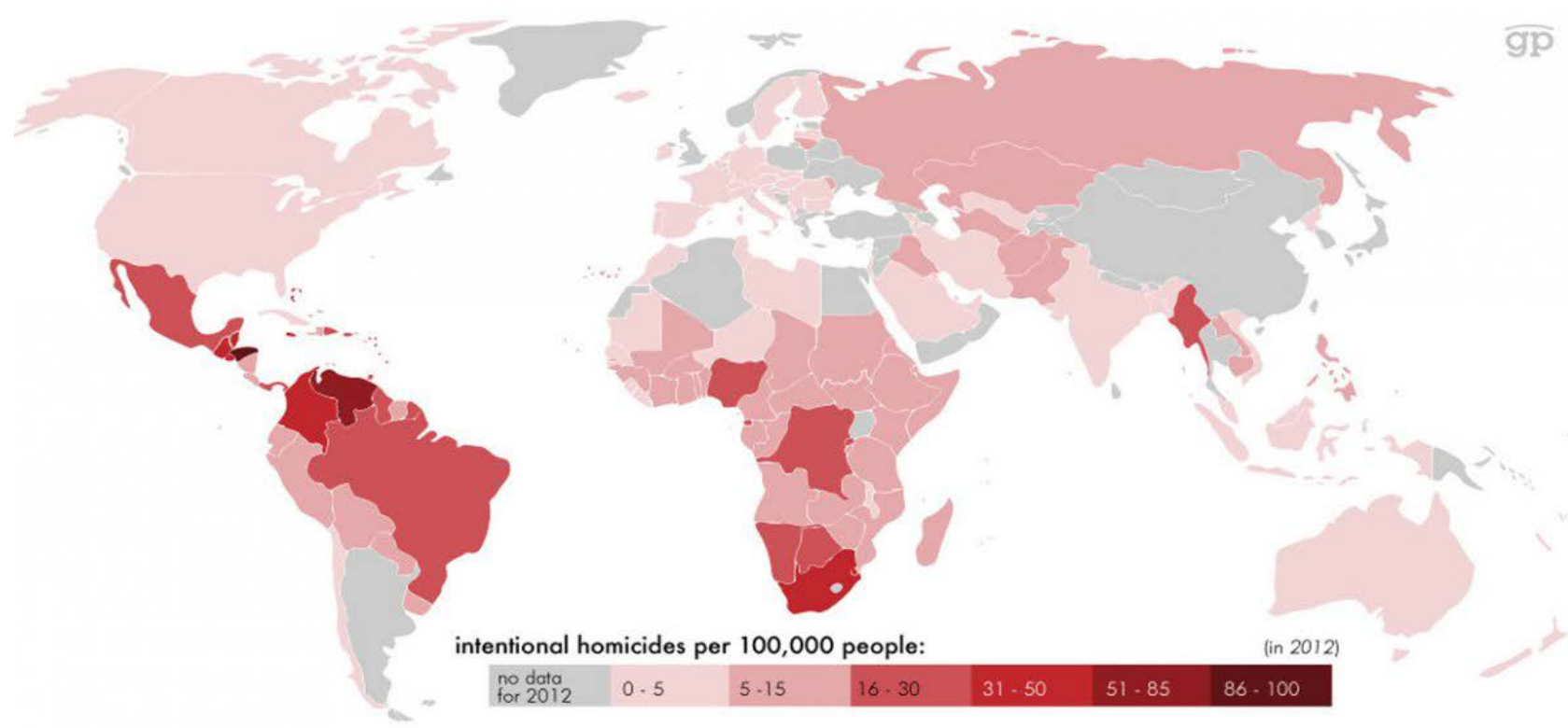

Top 12 countries by intentional homicides per 100,000 people:

\begin{tabular}{|c|c|c|c|c|c|c|}
\hline \#1. HONDURAS & 90.4 & $\# 4$ EL SALVADOR & 41.2 & \#7 SWAZILAND & 33.8 & $\# 10$ COLOMBIA \\
\hline \#2. VENEZUELA & 53.7 & \#5 GUATEMALA & 39. & \#8 ST. KITTS \& NEVIS & 33. & $\#$ H THE BAHAMAS \\
\hline \#3.BELIZE & 44. & \#6 JAMAICA & 0 & \#9. SOUTH AFRICA & 31. & \#12 TRINIDAD \& TOB \\
\hline
\end{tabular}

Figura 1. Tasa de homicidios por país en el mundo

Fuente: UN Office on Drugs and Crime. Extraída del sitio web: http://prodavinci.com/2014/11/26/actualidad/sepa-por-que-la-onuconsidera-que-venezuela-es-el-segundo-pais-mas-peligroso-del-mundo/

Sólo en Latinoamérica y el Caribe la tasa de homicidios por cada 100.000 habitantes es de 24,5, mientras que en Asia y el Pacífico es de 1,5 y en Europa y Asia Central de 3,1 (Ver figura 2). En 2012, 437.000 personas en el mundo fueron víctimas de homicidio, $33 \%$ de ellos en esta región que cuenta sólo con el 8\% de la población mundial. Cada año, 1 de cada 5 asesinatos en el mundo ocurren en Brasil, Colombia o Venezuela.

Según la revista Forbes en su edición de 2015, y también acorde con el número de homicidios por cada 100.000 habitantes, 42 ciudades de las 50 más violentas del mundo son latinoamericanas. El top 10 lo lidera también esta región, específicamente ciudades hondureñas, venezolanas, mexicanas, brasileñas y colombianas. Encabeza la lista San Pedro Sula en Honduras, seguida de Caracas, Acapulco, Joao Pessoa (Brasil), Distrito Central (Honduras), Maceió (Brasil), Valencia (Venezuela), Fortaleza (Brasil), Cali (Colombia) y Sao Luís (Brasil). 


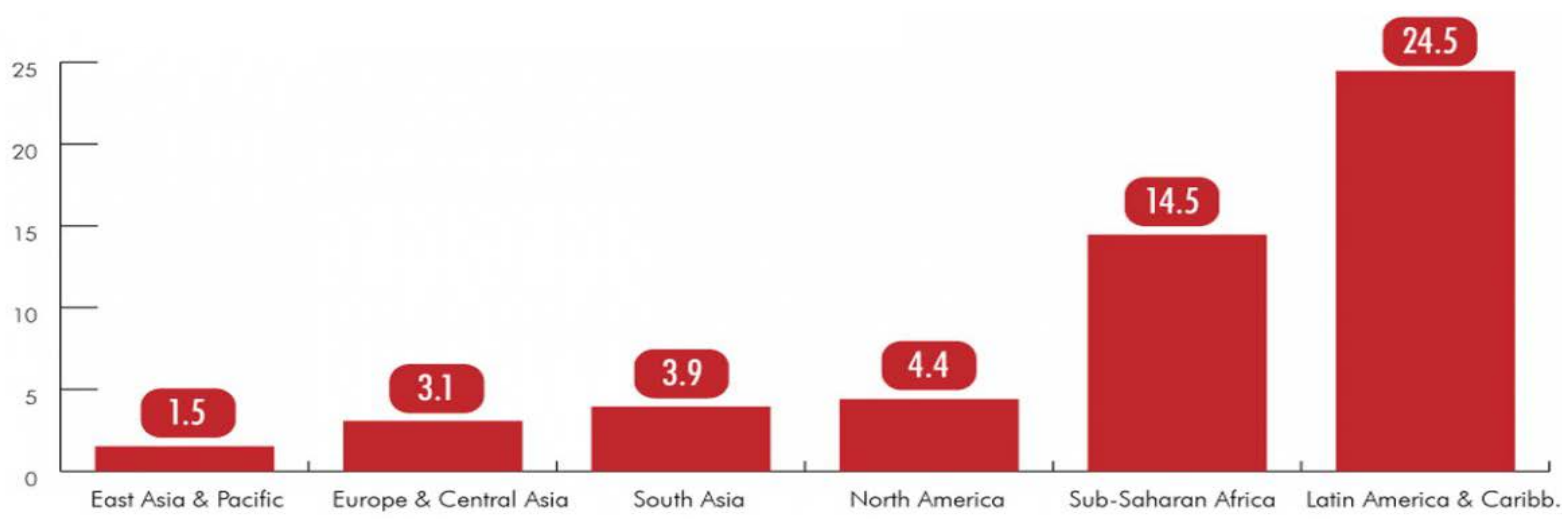

Figura 2. Tasa de homicidios por región ONU en el mundo

Fuente: UN Office on Drugs and Crime. Extraída del sitio web: http://prodavinci.com/2014/11/26/actualidad/sepa-por-que-la-onuconsidera-que-venezuela-es-el-segundo-pais-mas-peligroso-del-mundo/

El problema de la seguridad urbana aunque es global, parece bastante concentrado en la región de Latinoamérica y el Caribe. Y precisamente allí, parece que las respuestas a dicho problema han sido insuficientes, por no decir poco creativas. Los gobiernos locales lo han mirado dicotómicamente, bajo la eterna contraposición entre control y prevención, o el uno o la otra, pero no simultáneamente. De hecho, sobre la prevención hay poco interés, ya que no da lugar a resultados visibles a corto plazo, por lo que resulta políticamente menos atractiva. Pero la relación entre control y prevención no debe suponer una alternativa para garantizar la seguridad urbana; al contrario, debería plantearse como una relación complementaria, ya que el control puede atajar problemas inmediatos pero resulta poco sostenible a medio o largo plazo si no va acompañado de la prevención, y atender a ésta exclusivamente puede dejar de lado algo tan importante como la reacción pronta de la fuerza pública o la efectividad de la justicia.

De forma similar, al enfoque dicotómico, que separa control de prevención, el unidireccional, o sea la inseguridad vista únicamente desde la perspectiva de lo gubernamental, o en otras palabras, desde la acción meramente estatal y desde el uso legítimo de la fuerza, resulta absolutamente insuficiente. Un enfoque multidireccional, o multienfoque, puede asociarse a una perspectiva que aborde no sólo lo gubernamental, sino también lo social y lo físico, o sea, la seguridad urbana afrontada a la vez, desde el control, la prevención, y con ellos, desde lo gubernamental, lo social y lo físico.

A todo esto, y en el bienentendido de que una problemática global requiere de un enfoque global, han surgido varias acciones y manifiestos internacionales. Según la ONU, “... la seguridad ciudadana es la forma principal de la seguridad humana que garantiza derechos humanos fundamentales y atañe a la libertad, que es la esencia del desarrollo humano. En forma más específica, la seguridad ciudadana concierne a la protección de ciertas opciones u oportunidades de todas las personas -su vida, su integridad, su patrimoniocontra un tipo específico de riesgo (delito), que afecta la vida cotidiana de las víctimas" (ONU). Así mismo, el número 11 de los Objetivos del Desarrollo Sostenible, apela a "... lograr que las ciudades y los asentamientos humanos sean inclusivos, seguros, resilientes y sostenibles" (ONU).

Consecuentemente, el Programa de Naciones Unida para la Asentamientos Humanos, ONU-HÁBITAT, ha propuesto el pasado octubre en el marco de la Conferencia sobre la Vivienda y el Desarrollo Urbano Sostenible Hábitat III, una nueva agenda urbana mundial para las próximas dos décadas que recoge 6 principios, 4 de ellos asentados ya en el Objetivo 11 del Desarrollo Sostenible y dos nuevos: la participación y la compacidad. De acuerdo pues con la nueva agenda urbana, que ha de regir el destino de las ciudades del globo hasta el año 2036, éstas deberán encontrar un camino de inclusión, resiliencia, sostenibilidad, participación, compacidad y seguridad. Sobre este último un claro enfoque: "Una ciudad que no tiene fronteras para sus ciudadanos, donde los espacios públicos son la clave para construir comunidades plurales, evitando la estigmatización de grupos sociales" (ONU). La Organización de Naciones Unidas ha propuesto un enfoque físico para la seguridad, el del espacio inclusivo, que por ello es decididamente social.

La seguridad urbana es entonces una cuestión que por ser repetidamente local, es global, que debe afrontarse no sólo desde lo policial, sino desde la multidisciplinariedad y los enfoques múltiples y complementarios; es una cuestión que atañe tanto a la prevención como al control, y a la gobernanza, la gestión de la cohesión social y el tratamiento al espacio físico como espacio de convivencia e inhibición del delito. 


\section{EL PRINCIPIO DE TRANSVERSALIDAD DE LA SEGURIDAD URBANA: EL CONTEXTO GENERAL}

\subsection{Los principales actores: víctimas, victimarios y operadores}

Los actores de la seguridad no sólo incluyen víctimas y victimarios, también a los operadores de la seguridad, que pueden ser convencionales (el estado), o no convencionales (los sectores privado, social y hasta los propios victimarios). Esta telaraña, donde no hay una claridad meridiana en los roles, y donde cada tanto este rol puede ser transferido, traslapado o usurpado, es un escenario clave para una evaluación inicial de la cuestión.

Para entender la seguridad desde sus actores, debemos interpretarla desde la capacidad de influencia de esos actores, que en la mayoría de casos son entidades o grupos organizados. Esa capacidad de influencia otorga poder y legitimidad. Así, si la prestación de seguridad ya no está sólo en manos del Estado, sino también en grupos regulares o irregulares, privados o sociales, y todos ellos, con capacidad de poder legítima o ilegitima, estamos hablando de un gobierno nodal. La prestación del servicio, o su regulación, ya no está en manos de uno -el sector público o el Estado-, sino de muchos -el sector público, el sector privado y el sector social-.

En su libro Pensar la Seguridad, sus autores (Shearing y Wood, 2011) titulan el primer capítulo "De la práctica del gobierno estatal, a la práctica del gobierno nodal", lo que nos remite a la idea de que el poder ya no está centralizado -corriente del estado de bienestar-, ni siquiera descentralizado y privatizado -corriente del estado neoliberal-, sino multiplicado. He aquí la esencia del gobierno nodal. Explican, primero, que la práctica de gobierno no sólo es estatal, sino también civil y empresarial, y todas ellas ejercen influencia entre sí, y las implicaciones democráticas que representa esto para la práctica de gobierno, pues cada vez son más los cuestionamientos que se le atribuyen a un estado en su rol de proveedor y regulador de la seguridad. Además explican que el desarrollo de un modelo de práctica de gobierno nodal ofrece una visión de tendencias y formas de gobierno, que pueden o no estar articuladas. ${ }^{1}$ Cuando la articulación se produce, y cuando hay cooperación entre los actores implicados, es probable que sea producto de la acción de un estado ágil y efectivo, que entiende que el resultado de la seguridad ya no depende sólo de él, sino de la esencia misma de la gobernanza.

\subsection{Los factores de la inseguridad urbana: el síndrome}

Es asumible que la seguridad urbana tiene factores que la cuestionan (o dificultan, o simplemente, factores clave). También es asumible que puede producirse una respuesta violenta al conflicto que supone la ciudad como un conglomerado social y mixto. Es por tanto asumible que si dicha respuesta es un delito, detonada además por unos factores de riesgo, éstos pueden ser previamente tratados para evitar la detonación del delito. El conflicto, como parte esencial e inequívoca de la ciudad, no es por sí mismo algo malo y como tal evitable. Lo que sí es pernicioso y como tal debiera evitarse es la respuesta violenta al conflicto, o crimen, detonado por factores de diversa índole: gubernamentales, socioeconómicos o físico-territoriales.

A grandes rasgos podría decirse que los factores gubernamentales están generalmente asociados a una baja capacidad institucional, entendida esta como el aparato estatal incapaz de ofrecer seguridad a la ciudad, y traducida a veces en acciones tan simples como la reacción policial tardía, o la poca efectividad y fortaleza de la justicia. Paralelamente los factores de índole socioeconómico podrían estar asociados a actores con capacidad económica y de coacción como las mafias vinculadas al narcotráfico y a su eterna disputa por el control territorial, o a problemas sociales tan profundos como la pobreza, la desigualdad, la falta de acceso a la educación básica, o el desempleo. Finalmente los factores físico-territoriales podrían asociarse a un planeamiento urbano mal encauzado, como los que detonan en ciudades con comunidades

\footnotetext{
1 "El neoliberalismo y el sueño de acción estatal a distancia, que representa, son sólo un parte de una historia más extensa, la de la 'práctica de gobierno nodal'... la visión Estadocéntrica logró sobrevivir al pasaje del pensamiento centrado en el Estado de Bienestar al pensamiento neoliberal. Mientras que los partidarios del Estado de Bienestar conceptualizaban a los estados como autoridades y prestadoras de gobierno, los pensadores neoliberales buscaron separar la función de 'autoridad' de la de 'prestador' (Bayeley y Shearing, 2001). La idea queda expresada en la sencilla pero potente descripción a los Estados, 'timonear' más y 'remar' menos (Osborne y Gaebler, 1992)... La realidad de la práctica del gobierno nodal... no es sólo que pasamos de un gobierno de mando y control a formas de gobierno no estatal indirectas que operan por medios de mecanismos de mercado o de persuasión, asociadas a la movilización del tercer sector. Lo que tenemos es un complejo conjunto de relaciones en los que los 'timoneles' y los 'remeros' entablan relaciones y alinean sus intereses... El viraje conceptual por el que abogamos, entonces, reconoce la diversidad de entidades, a las que denominamos 'nodos'... Un nodo debe tener alguna forma institucional... una pandilla callejera puede ser u nodo, como lo puede ser una comisaria o un turno determinado en un cuartel de bomberos, que funcionan como auspicios o prestadores de bienes de seguridad, o como ambas cosas. Para nosotros 'el Estado' ya no es la única, o en algunos casos, la principal fuente de autoridad, ni en el ámbito interno, ni en el sistema internacional' (Hall y Biesteker, 2002)" (Shearing y Wood, 2011)
} 
cerradas ('Gated Communities' como son comúnmente conocidas), o con una separación funcional marcada, o peor aún, de clases sociales, o a gran escala, con barrios aislados o guetificados. De igual manera, factores físicos que afectarían la pequeña escala y la calidad urbano-ambiental, tales como la oscuridad del espacio público, la vegetación espesa y bloqueadora visual, o la falta de mantenimiento que provoca su detrimento progresivo.

Hoy en América Latina la seguridad urbana es una cuestión de primera importancia nacional volcada a lo local, es decir, tiene grandes dimensiones y se manifiesta en las grandes ciudades. Las de Honduras, Guatemala y El Salvador son ciudades inseguras, fundamentalmente por los remanentes de guerras civiles internas. En Venezuela una crisis aguda a nivel nacional sitúa hoy sus ciudades entre las más inseguras del mundo. En México, el problema del narcotráfico, que alcanza escala nacional, también desemboca necesariamente en las ciudades. En Colombia, las ciudades son remanentes de una guerra civil interna de más de medio siglo y de un problema que allí parece perpetuo: el narcotráfico. Es por ello, que la cuestión de la seguridad de las ciudades latinoamericanas, aunque explicable desde los factores de riesgo, es explicable también como los remanentes de conflictos nacionales que concentran su furia en las grandes ciudades.

En conclusión, aunque el conflicto es inherente a la ciudad, se dan respuestas violentas, que constituyen reflejos de inseguridad, producto de problemas políticos, sociales y económicos, mayores o menores, de la desgobernanza de dichos problemas, y de un espacio que la facilita.

\subsection{Los enfoques de la seguridad urbana: una aproximación tripartita}

Los enfoques aislados no generan resultados adecuados. Hay dos, ya comentados, sobre los que comúnmente se trabaja: el asociado al uso de la fuerza y como tal, ejercicio legítimo del estado, y el relacionado con los programas sociales en favor de la convivencia. Son insuficientes si actúan por separado y sin la inclusión del espacio como escenario de la seguridad, y sin un concepto claro de gobernanza en red y de promoción de la cohesión social.

Las categorías que vinculan factores de riesgo de una misma fuente, son los 3 ámbitos de un 'multienfoque': el gubernamental, el socioeconómico y el físico-territorial. De esta mirada múltiple y complementaria se deriva un enfoque unificador e integral; de ahí la mención a un "principio de transversalidad", y en este caso representado en un triángulo de seguridad urbana, que aunque pondera el espacio físico como la plataforma, también incluye en igual medida la gobernanza y la acción social.

\section{El ámbito gubernamental:}

\section{La gobernanza nodal}

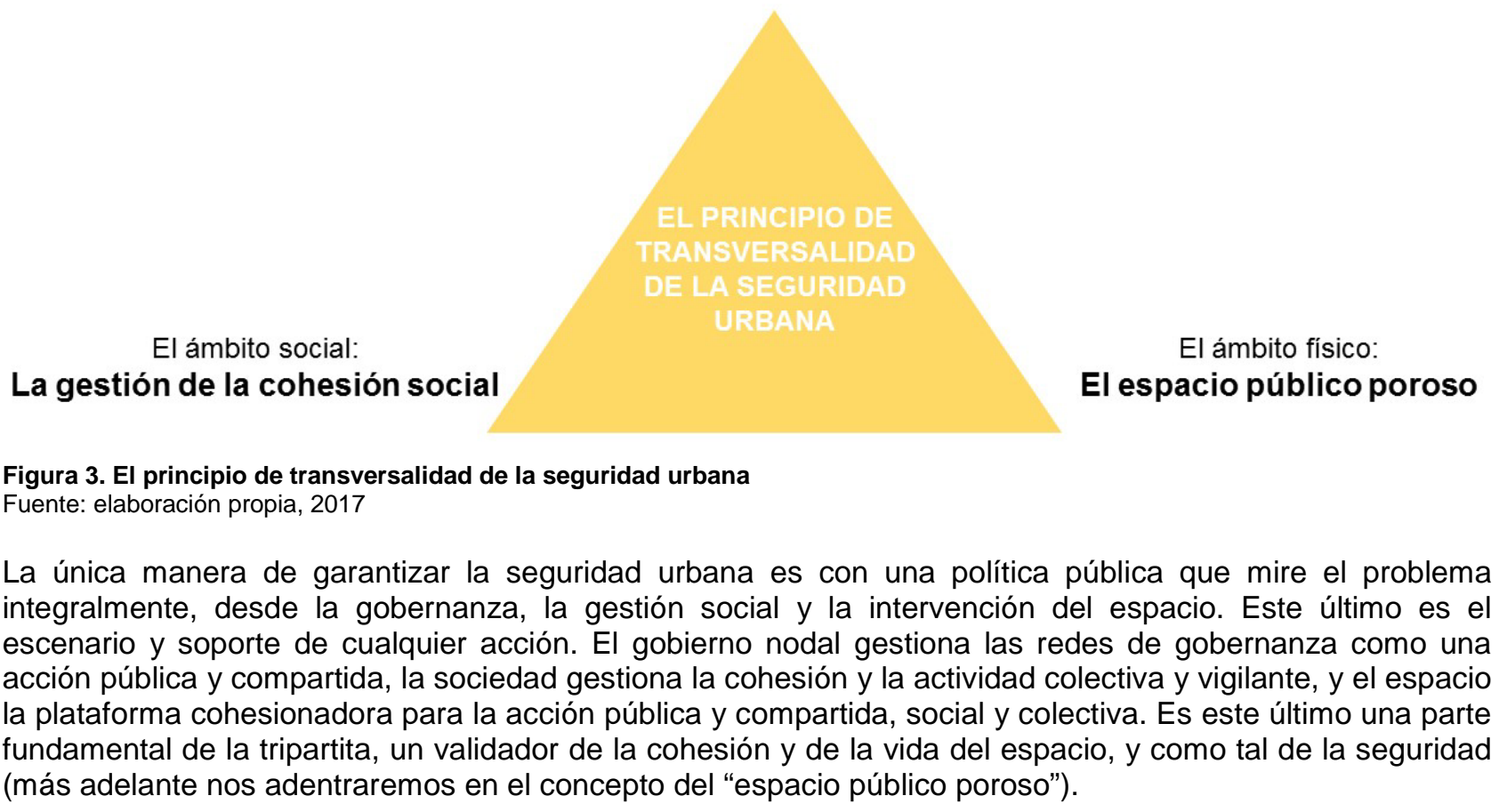

Figura 3. El principio de transversalidad de la seguridad urbana

La única manera de garantizar la seguridad urbana es con una política pública que mire el problema integralmente, desde la gobernanza, la gestión social y la intervención del espacio. Este último es el escenario y soporte de cualquier acción. El gobierno nodal gestiona las redes de gobernanza como una acción pública y compartida, la sociedad gestiona la cohesión y la actividad colectiva y vigilante, y el espacio (más adelante nos adentraremos en el concepto del "espacio público poroso"). 


\section{ANTECEDENTES DE LA SEGURIDAD ASOCIADA AL ESPACIO PÚBLICO: EL CONTEXTO FíSICO}

Uno de los enfoques asociados al concepto de seguridad urbana, y una parte del "triángulo virtuoso" es el tratamiento al espacio, especialmente el público, que es el que tiene incidencia en masas de gente. El delito se manifiesta de diversas maneras, pero siempre con tres componentes en común: una víctima, un victimario y un espacio físico. Este último, si bien no lo provoca, si lo facilita o lo inhibe.

\subsection{Los antecedentes de la seguridad en relación con el espacio público}

En la década de los 50 surgen las teorías de la clase social, que asocian el delito con "... los precios del mercado, tradiciones coyunturales y políticas municipales de vivienda social, factores que condicionaban a los habitantes de ciertas zonas y propiciaba que la delincuencia no dependiera del entorno físico sino de las personas" (Ayuntamiento de Madrid, 2007).

Antes de la década de los 60 no había una vinculación directa entre delincuencia y entorno físico; por el contrario, los enfoques inherentes a la seguridad ciudadana eran sólo de control y reacción estatal, más que de prevención. No es hasta 1961, que Jane Jacobs introduce por vez primera el concepto de 'Los Ojos de la Calle' (Jacobs, 1961), en su libro The Death and Life of Great American Cities, donde hace referencia a la vigilancia social informal del espacio público, y, por consiguiente, a la relación seguridad y espacio. Además, en esta década se producen ciertas aproximaciones al control del espacio urbano a través de los sistemas de orientación e iluminación.

Entrada la década de los 70, Oscar Newman publica Design Guidelines for Creating Defensible Space, en el que hace alusión a la 'Teoría del Espacio Defendible' (Newman, 1972), que aborda conceptos urbanísticos para la apropiación del espacio público por parte de la comunidad, como una herramienta fundamental para el sustento de la seguridad barrial.

En 1978, inspirado en la teoría de Newman, nace el concepto de 'Crime Prevention Through Environmental Design -CPTED' (Jeffery, 1978), traducido hoy como Prevención Situacional, que “... no es otra cosa que la necesidad de reducir las oportunidades a la violencia en las victimas (actividades rutinarias) a partir de los espacios o sitios proclive a la realización del crimen (diseño urbano)" (Carrión, 2008). Este concepto aborda básicamente cinco principios: a) el control de accesos, b) la vigilancia informal, c) el refuerzo territorial, sentido de apropiación o los lazos afectivos entre habitantes de un mismo barrio, d) la imagen y el mantenimiento de los espacios públicos, y e) la participación comunitaria. En la misma década, la llamada 'Escuela de Chicago', explica la delincuencia como resultado de tres características: el nivel de ingresos, la movilidad residencial y la "heterogeneidad étnica". Es decir "... cuanto más pobre, menos estable y más desintegrado socialmente sea el barrio, habrá más delincuencia" (Ayuntamiento de Madrid, 2007).

Ya en la década de los 80 nace la denominada 'Teoría de las Ventanas Rotas'2 (Wilson \& Kelling, 1982), que explica la delincuencia desde el deterioro progresivo, social y físico, de un barrio por falta de mantenimiento. Una ventana rota es sólo el principio del proceso de detrimento de una zona de la ciudad.

A partir de la década de los 90, tanto en el Reino Unido, como en los Estados Unidos y en los Países Bajos, se adoptan medidas públicas para afrontar la inseguridad urbana, con los principios de las teorías precedentes, en especial la del CPTED (Crime Prevention Through Environmental Design). En 1989 la Policía del Reino Unido implementó el programa Secured by Design (SBD), que se "... centra en el diseño y la seguridad para las nuevas y renovadas viviendas, locales comerciales y aparcamientos, así como el reconocimiento de los productos de seguridad de calidad y proyectos de prevención del delito. Es compatible con los principios de "diseñar el crimen" a través de la seguridad física y sus procesos" (Sanz, 2008). En 1993, en los Estados Unidos, se suma el Departamento de Educación de Florida con el fin de adoptar los principios del CPTED aplicado a prácticas de diseño y construcción de escuelas y de sus entornos. Así mismo, en 1995, los Países Bajos implementan el Certificado de Diseño Seguro, que busca asimismo la aplicación de los principios del CPTED como una certificación estatal de diseño arquitectónico y urbano. En éste último se analizan: a) la organización del barrio; b) el trazado; c) el diseño del entorno residencial; d) la gestión y participación de los vecinos y e) el edificio en sí mismo. Cabe destacar también la

\footnotetext{
${ }^{2}$ La percepción de seguridad es muy subjetiva y está relacionada con la visibilidad y con la vigilancia más que con los resultados objetivos. La conocida como 'ventanas rotas', que parte de lógica causal establecida entre el desorden callejero (espacio público) y la violencia; un desorden o descuido que nace del desinterés de reparar una ventana rota (algo ínfimo), que luego se convierte en un basurero público (algo máximo), lo que a su vez convoca a pandilleros, mendigos, alcohólicos y drogadictos y estos a reclamos del vecindario por seguridad (Carrión, 2008).
} 
Teoría de la Criminología Ambiental (Paul and Patricia Brantingham, 1991), la cual incorpora cinco principios de contexto como fuentes de análisis de un hecho delictivo: el espacio, el tiempo, la ley, la víctima y el victimario.

Del año 2000 en adelante aparecen términos relacionados con la geografía, tales como el de 'Geografía de la Violencia' o 'Geografía del Crimen', y más recientemente el de 'Geoprevención', que se soporta en los Sistemas de Información Geográfica -SIG como herramienta para el análisis y prevención del crimen. Entre otros presenta asimismo criterios de evaluación como los concebidos por el CPTED: “... los espacios y tipos de usos, la vigilancia natural, la visibilidad, la lluminación, el control de accesos, la identidad del espacio público, la participación y sentido de pertenencia del espacio público y el mantenimiento" (Sanz, 2008). Además, el autor añade que "... sin ningún género de dudas, la geografía tiene una gran potencialidad explicativa a la hora de relacionar la dimensión espacial de los comportamientos delictivos y violentos con otros caracteres de base social o demográfica" (Sanz, 2008).

De igual manera, los conceptos asociados más a la gobernanza, tales como el 'Gobierno de la Seguridad' (Velásquez, 2008) o el 'Gobierno Nodal' (Shearing y Wood, 2011) hacen referencia como condición determinista a los actores de la (in)seguridad, y con ellos, al espacio físico en el que se mueven. Es decir, las teorías, conceptos y acciones públicas ya no sólo son sujetos aislados y dignos de estudio desde disciplinas específicas, sino desde un panorama más amplio y complejo de gobernanza. En específico "... el Gobierno de la Seguridad se basa en 4 aspectos: primero, análisis de la conflictividad, segundo, mapa de actores estratégicos, tercero, los espacios o nodos de actividad entre actores, y cuarto, las reglas que rigen la acción entre esos actores" (Velásquez, 2008). La seguridad y sus 'atributos físicos' ya no sólo son abordables desde las formas urbanas, sino desde las formas sociales y políticas.

En cierta medida estas teorías y aproximaciones han sido acumulativas, es decir, las teorías de Jacobs y Newman como pioneras, que coinciden, primero, en frenar el temor a la delincuencia, y segundo, en intervenir el medio físico urbano, inspiraron las acciones subsiguientes. El siguiente cuadro expone algo de esta evolución:

\begin{tabular}{|l|l|l|l|}
\hline Año & Autor & Concepto & Enfoque \\
\hline 1961 & Jane Jacobs & $\begin{array}{l}\text { Concepto de los 'Ojos en la } \\
\text { Calle' }\end{array}$ & $\begin{array}{l}\text { La vigilancia informal del espacio público y su } \\
\text { ocupación a través de la diversificación de los } \\
\text { usos del suelo }\end{array}$ \\
\hline 1972 & $\begin{array}{l}\text { Oscar } \\
\text { Newman }\end{array}$ & $\begin{array}{l}\text { 'Teoría del Espacio } \\
\text { Defendible' }\end{array}$ & $\begin{array}{l}\text { La prevención del crimen y la seguridad barrial a } \\
\text { través de la apropiación comunitaria del espacio } \\
\text { público }\end{array}$ \\
\hline 1975 & $\begin{array}{l}\text { Escuela de } \\
\text { Chicago }\end{array}$ & $\begin{array}{l}\text { Tesis del nivel de ingresos, } \\
\text { movilidad residencial y } \\
\text { heterogeneidad étnica }\end{array}$ & $\begin{array}{l}\text { La delincuencia asociada al barrio aislado, pobre } \\
\text { y étnicamente heterogéneo. }\end{array}$ \\
\hline 1982 & $\begin{array}{l}\text { Wilson \& } \\
\text { Kelling }\end{array}$ & Concepto de CPTED & $\begin{array}{l}\text { La prevención del crimen a través del diseño } \\
\text { ambiental }\end{array}$ \\
\hline 1989 & $\begin{array}{l}\text { Reino Unido } \\
\text { Rotas'a de las Ventanas }\end{array}$ & $\begin{array}{l}\text { Los entornos urbanos en buenas condiciones de } \\
\text { mantenimiento, provocan una disminución del } \\
\text { crimen }\end{array}$ \\
\hline 1991 & $\begin{array}{l}\text { Paul and } \\
\text { Patricia } \\
\text { Brantingham } \\
\text { Desítica de 'Secured by }\end{array}$ & $\begin{array}{l}\text { 'SBiminología Ambiental } \\
\text { y sus procesos' }\end{array}$ & $\begin{array}{l}\text { Los factores y el contexto (espacio, tiempo, ley, } \\
\text { víctima y victimario) influyen en la actividad } \\
\text { criminal }\end{array}$ \\
\hline 1993 & $\begin{array}{l}\text { Departamento } \\
\text { de Educación } \\
\text { de Florida }\end{array}$ & $\begin{array}{l}\text { Política de los principios del } \\
\text { CPTED aplicada al diseño } \\
\text { arquitectónico y urbano }\end{array}$ & $\begin{array}{l}\text { La aplicación de los principios del CPTED como } \\
\text { herramienta de diseño en escuelas de la Florida }\end{array}$ \\
\hline 1995 & $\begin{array}{l}\text { Países Bajos } \\
\text { Política de 'Certificado de } \\
\text { Diseño Seguro' }\end{array}$ & $\begin{array}{l}\text { La aplicación de los principios del CPTED como } \\
\text { certificación estatal de diseño arquitectónico y } \\
\text { urbano }\end{array}$ \\
\hline 2001 & $\begin{array}{l}\text { Escuela de } \\
\text { Chicago }\end{array}$ & $\begin{array}{l}\text { Concepto de } \\
\text { 'Geoprevención' }\end{array}$ & $\begin{array}{l}\text { La utilización de los Sistemas de Información } \\
\text { Geográfica -SIG como herramienta para el } \\
\text { análisis y prevención del crimen }\end{array}$ \\
\hline
\end{tabular}

Figura 4. Teorías y conceptos aplicados de la seguridad urbana y su relación con el entorno físico de la ciudad Fuente: elaboración propia, 2015 
Así pues, el precursor concepto de 'Los ojos en la calle' o 'Vigilancia social informal del espacio público' (Jacobs, 1961), y sus subsecuentes 'Teoría del Espacio Defendible' (Newman, 1972), la 'Prevención del Crimen a Través del Diseño Ambiental' (CPTED), en su sigla en inglés (Jeffery, 1978) y la 'Teoría de las Ventanas Rotas' (Wilson y Kelling, 1982), son las que han marcado una clara pauta de entendimiento de esta relación. De las cuatro principales, las dos primeras apuntan a la seguridad urbana a través de la ocupación del espacio público por la gente, y las dos segundas apuntan a la intervención física del espacio público $^{3}$ (Ver figura 6). En otras palabras, y según los cuatro conceptos, esta relación debe ser necesariamente entendida como la intervención del espacio público para que pueda ser ocupado por la gente; ahí entonces habrá más seguridad. El aquí denominado concepto 'Fronteras Blandas' recoge esta idea e indaga sobre algunas potenciales acciones urbanísticas dadoras de gente al espacio público; propósito estéril mientras la ciudad esté gobernada por fronteras infranqueables.

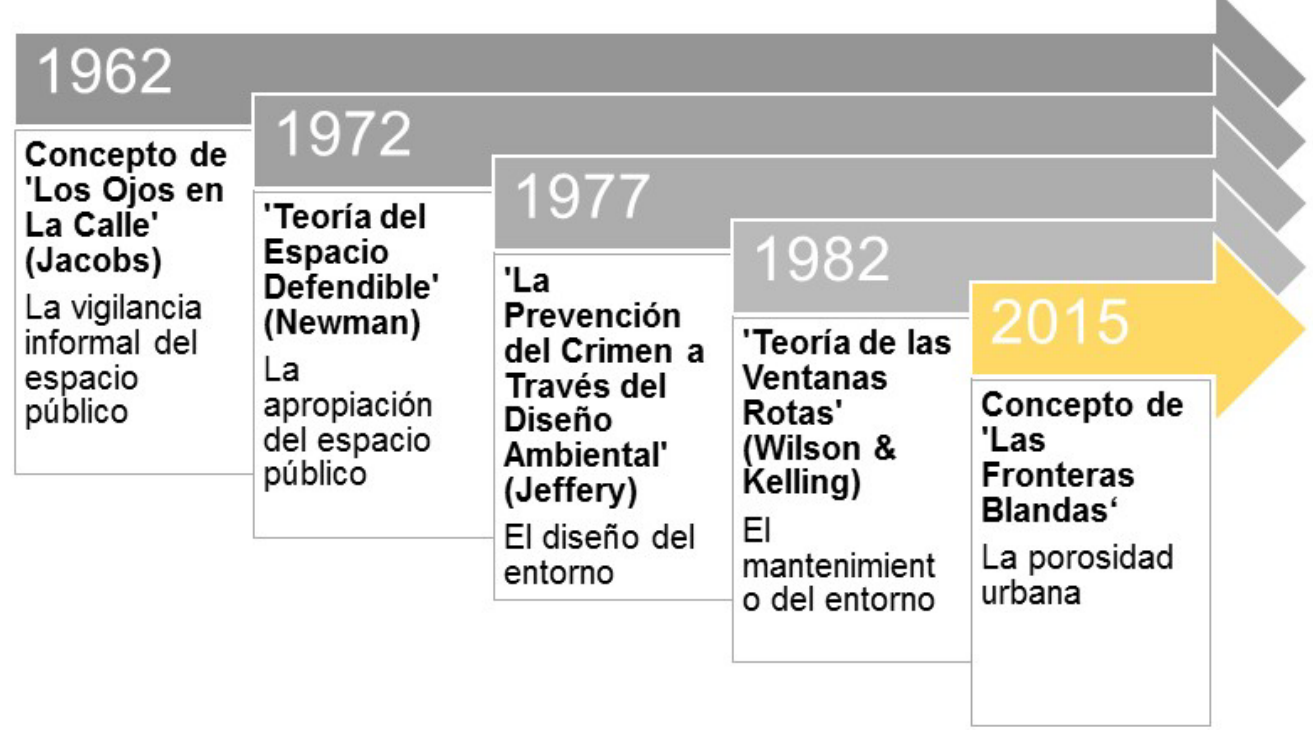

Figura 5. Evolución de conceptos precursores e introducción del concepto de fronteras blandas Fuente: elaboración propia, 2015

\section{LAS FRONTERAS BLANDAS: UN NUEVO ENFOQUE DE SEGURIDAD EN EL ESPACIO PÚBLICO}

\section{1 ¿Qué son las Fronteras Blandas?}

Para hablar de fronteras blandas primero deberíamos remitirnos al concepto de 'fronteras', en este caso urbanas, puesto que es el ámbito que nos convoca. Estás son límites intersticiales constituidos como grandes interruptores de la continuidad urbana, mayormente de flujos peatonales que ocupan el espacio público, lo significan y le dan vida. Autopistas, vías, ferrovías, y hasta cuerpos de agua, son potencialmente límites, dan lugar a espacios sobrantes, incomunicados y desconectados del sistema urbano, y por ello espacios muertos. De igual manera, los límites entre el espacio público y privado, constituidos como fronteras barriales pero a una escala más cercana al ciudadano, tal como los paramentos donde terminan los edificios y comienza el espacio público (muros o cercados), pueden devenir en fronteras inaccesibles que matan el espacio público.

Las Fronteras Blandas entonces apelan principalmente al concepto de porosidad urbana, entendido como un componente esencial de la seguridad, en tanto que impide la muerte de espacios urbanos residuales y permite la integración e interacción de los sistemas urbanos, y, por consiguiente, de flujos de gente y de lugares de permanencia, de ocupación y vida del espacio público. En general, una frontera dura es impermeable, mientras que una frontera blanda es permeable, porosa, y da pie a que la gente, concentrada y agrupada mayormente en el espacio privado, pase al público y lo ocupe. Este concepto alude esencialmente al enfoque físico de la seguridad. Es en principio una respuesta conceptual al entorno urbano como facilitador de seguridad.

\footnotetext{
${ }^{3}$ Casi siempre los intentos de prevención de la delincuencia relacionados con el diseño urbano se han basado en dos premisas esenciales: en primer lugar en la llamada 'vigilancia informal' (ver y ser visto). Y en segundo lugar en el 'control del espacio urbano' (buenos sistemas de orientación e iluminación adecuada)... Estos dos principios, vigilancia informal y control del espacio urbano han sido adoptados con un cierto interés por el diseño urbano, aunque no puede decirse lo mismo respecto a la planificación (Ayuntamiento de Madrid, 2007)
} 
Repasando las teorías de la relación entre seguridad y entorno urbano, el concepto de 'Los Ojos de la Calle' apela a la seguridad mediante la vigilancia informal; la 'Teoría del Espacio Defendible' mediante la apropiación del espacio público; el CPTED mediante el diseño del entorno; y la 'Teoría de las Ventanas Rotas' mediante el mantenimiento del entorno. Las dos primeras apuntan a la seguridad urbana a través de la ocupación del espacio público por la gente, y dos segundas a la intervención física del espacio público, a su calidad y a su mantenimiento. El concepto de 'Fronteras Blandas' recoge entonces la idea rectora de que un espacio ocupado por la gente deviene más seguro, y ésta, la ocupación del espacio, pasa necesariamente por el urbanismo.

Un espacio urbano ocupado es un espacio vivo. Por lo tanto, el simple concepto de 'ocupación' exalta la idea del 'espacio urbano vivo' y como tal integrador y cohesionador social. Porque difícilmente hay seguridad sin espacio urbano vivo, es decir, con gente que es el contenido propio del espacio; y éste debe ser intencionadamente amable y poroso para que la gente llegue a él. Entonces, hay más seguridad en el espacio vivo, no en el muerto, no en el residual, no en el excluido. Y la inseguridad busca acomodarse en espacios muertos y fronterizos, residuales y desprovistos de gente, justo ahí donde se cortan los sistemas urbanos.

Contrastadamente es posible entender el concepto de Fronteras Blandas, asociado a la porosidad, como antagónico de la 'Teoría del Espacio Defendible', asociado más a la apropiación del espacio, y como su nombre indica, a la defensa del espacio. La gran perversión de este último, es que 'lo defendible' tiende a ser entendido como 'lo cerrado', y cuando el espacio urbano se cierra (así sea por fronteras simbólicas) como un entendido de la apropiación, el espacio público remanente, fuera del 'defendido', se muere ya que habría lugares sin 'dolientes' o sin 'defensores'. Lo 'defendible' y su generalizada concepción, las zonas donde hay más muros, más rejas, más zanjas, más brechas, más cercas residenciales, más barreras, y más protección al espacio privado, a 'mi espacio' son generalmente más inseguras, porque el espacio privado protegido hace que el espacio público sea de nadie. He aquí el hecho de la porosidad, romper barreras físicas y visuales para arropar el espacio público.

El espacio físico facilitador del delito suele estar desprovisto de gente y aislado de los sistemas urbanos, es impermeable, disperso y fragmentado, y promotor de segregación social. Por el contrario, el espacio físico inhibidor del delito, por el que el concepto de fronteras blandas propende, está lleno de vida, y como tal de gente, integrado a los sistemas de ciudad, y tan permeable como para garantizar flujos constantes de gente y lugares de permanencia, de cohesión social y de presencia institucional. Es poroso, integrado y mezclado.

\subsection{Los 3 principios de las Fronteras Blandas}

El concepto de Fronteras Blandas nace de exaltar la idea del espacio público para otorgarle contenido y vida, y por ello, extensión de la idea rectora de seguridad. Hay 3 principios que lo fundamentan: la porosidad, la integración y la mezcla urbanas. Si bien hacen referencia a una escala barrial, también son perfectamente adaptables a una escala de ciudad, incluso metropolitana.

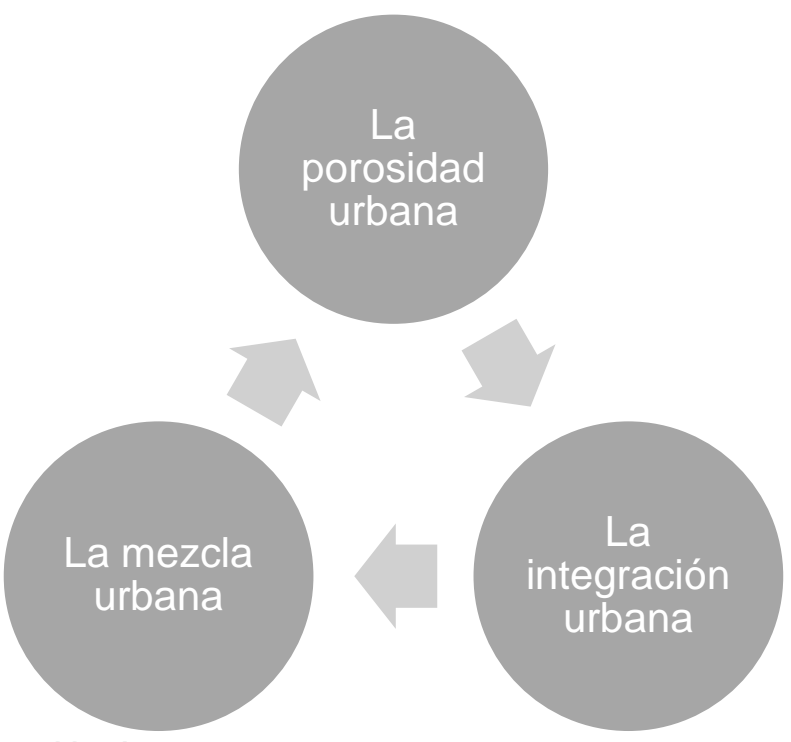

Figura 6. Los 3 principios de las fronteras blandas

Fuente: elaboración propia, 2017 


\subsubsection{La porosidad urbana}

La porosidad entre el espacio público y privado se traduce como la continuidad de accesos al espacio privado desde el público. Hablamos de una porosidad física, garante de la vida continuada en el espacio público. Pero también, y no menos importante, está la permeabilidad visual, uno de los componentes de la 'vigilancia informal' (Jacobs, 1961), que está dada por la capacidad de ver, desde el espacio privado, lo que pasa en el público (ventanas, ventanales, arbustos, etc.). Al espacio público hay que llenarlo de gente, y esto sólo será posible mientras se garanticen flujos desde el espacio privado.

Al respecto Walter Benjamín es quien introduce por primera vez el término porosidad en referencia al medio físico de la ciudad al expresar que "... cuando un lugar es poroso, permite que la vida urbana se llene de contenido cultural, abre múltiples canales de comunicación y entrega a los transeúntes paquetes riquísimos de significación. Un lugar vivo es un lugar poroso. Al contrario, aquellos lugares en donde es imposible la porosidad, tarde o temprano enferman y mueren. Las calles amuralladas por los guetos voluntarios de vivienda o los bordes lisos de las industrias y las bodegas, por ejemplo, evitan que los transeúntes tengan necesidad de pasar por ahí, no hay donde estar, no hay nada que ver, están vacíos de contenido significativo, por lo tanto, tienden a ser inseguros y a generar impresiones de abandono y descuido" (Bejamín, 2011)

\subsubsection{La integración urbana}

De la porosidad entre el espacio público y privado nacen los sistemas, llamados a efectos de este concepto, a estar integrados e interactuados. Sólo ahí hablaremos de continuidad, y con ella de la eliminación de espacios residuales que crean inseguridad. Los sistemas urbanos a efectos del concepto de las Fronteras Blandas, abarcan los componentes territoriales de la ciudad en espacial los reflejados a escala de barrio, ya que la porosidad está especialmente definida a esta escala: el sistema natural y de espacios abiertos barriales, el sistema de transporte público y vial penetrable en el barrio, el sistema de centralidades barriales y el sistema de equipamientos y servicios barriales; todos ellos servidos y validados por el uso residencial.

Este principio intenta además explicar que los sistemas barriales deben ser necesariamente integrables a los sistemas urbanos. Así el barrio deja de ser una isla urbana, un gueto fronterizado por lo físico y por lo simbólico. Las 'grandes islas urbanas', o grandes 'constelaciones discontinuas de fragmentos espaciales' (Carrión, 2008), dañan la ciudad y generan zonas fragmentadas y por ende inseguras. Ahí, las Fronteras Blandas que permean la potencial barrera entre el espacio público y privado, que integran los sistemas urbanos, encuentran sentido.

La compacidad es también otro concepto asociado a la integración urbana como contraposición de la dispersión y desintegración, producto de la planificación urbana, o simple producto del crecimiento urbano. El tejido compacto es el tejido de la ocupación del espacio público y por tanto, de la vigilancia informal, también de su apropiación o 'defensa' (Newman, 1972).

\subsubsection{La mezcla urbana}

El concepto de mezcla urbana recoge la mezcla de usos y social, supone la inclusión y la garantía de ocupación del espacio público mediante articulación de usos del suelo. La mezcla social hace referencia a la vivienda sin números y/o estratificaciones, condición determinante de cohesión e integración social, y como tal de barrios más seguros. El concepto de mezcla urbana se opone al de segregación que habla de la separación entre clases sociales, e incluso al de zonificación estricta, -allá los pobres, aquí los ricos; allá la industria, aquí la recreación; allá el trabajo, aquí la vivienda-. Si bien se empieza a superar el paradigma de zonificación clásico, que implica una tajante separación de usos, y como tal una ciudad de constelaciones y zonas desocupadas, no es el caso de la segregación, puesto que aún es evidente en muchas ciudades latinoamericanas.

\subsection{Tipos de fronteras}

\subsubsection{Las fronteras de la ciudad y las fronteras de barrio}

Si buscamos ejemplificar en la ciudad el concepto, podríamos buscar fronteras que impiden la continuidad de los sistemas urbanos, y por ende, la generación de espacios muertos, en declive y fuera del 'tejido urbano', término que ilustra bastante bien la condición de porosidad en contraposición de la fragmentación. 
El tejido urbano, tal como su nombre indica, está tejido y no destejido, cuando está destejido es cuando aparecen zonas proclives a la inseguridad, zonas de nada ni de nadie, donde la inseguridad se alimenta.

Existen dos tipos de fronteras urbanas: unas a escala de ciudad, grandes barreras urbanas como las grandes vías o carriles de tren a nivel de calle, claramente visibles; otras a escala de barrio, pequeñas barreras urbanas que impiden la permeabilidad entre el espacio público y privado, como las urbanizaciones cerradas o equipamientos con pocos accesos, como escuelas. Como fronteras, éstas son un tanto invisibles, pero igual o más dañinas, porque suponen la muerte del espacio público.

En favor de la seguridad urbana, las acciones potenciales de 'ablandamiento' de estas fronteras suponen tejer de nuevo los sistemas urbanos y hacerlos porosos, atraer gente al espacio público y darle vida. Sólo ahí se recuperarán los flujos y se dispondrá de lugares de permanencia, y con ello, de mayor seguridad. Con las acciones que podríamos denominar acciones de 'ablandamiento' podremos ejemplificar mejor cuáles pueden ser las fronteras dañinas y las operaciones que las hacen porosas llevadoras de contenido al espacio público, un ejemplo de ello es Medellín, ampliado en el apartado 4.4.

\subsubsection{Las fronteras de ciudad y las acciones de 'ablandamiento'}

Para el primer tipo, grandes barreras urbanas, algunas acciones de 'ablandamiento' podrían ser: primero, los sistemas lineales públicos. Grandes brechas, ríos, vías, muros, todos generalmente inaccesibles, pueden ser objeto del emplazamiento de parques lineales o de líneas de transporte que tejan lo fragmentos que alguna vez estuvieron separados por la brecha urbana, Colombia; segundo, los servicios 'ancla', grandes equipamientos o superficies comerciales, que ubicadas en extremos opuestos o alejados generan una tensión entre sí mismas y con ellas un flujo continuado de peatones, funciona como un centro comercial en donde se ubican las grandes tiendas en extremos; tercero, el sistema de vacíos urbanos, la sistematización de espacios abiertos aislados unidos articulados a equipamientos y estaciones de trasporte público garantizarán la vida del espacio público.

\subsubsection{Las fronteras de barrio y las acciones de 'ablandamiento'}

Para el segundo tipo, pequeñas barreras de barrio, algunas acciones de 'ablandamiento' podrían ser los equipamientos y su uso social, equipamientos que gracias a su 'multifunción' amplían su espectro horario y extienden la vida del espacio público. También podrían serlo la vivienda mixta, la antítesis de la segregación social; el pequeño comercio de barrio, una operación contundente de porosidad entre el espacio público y privado y de vigilancia informal. Todas estas operaciones articuladas, componen un gran sistema urbano, más sólido y más seguro.

\subsection{Las Fronteras Blandas en Medellín y el urbanismo social: sólo un ejemplo de conceptos}

En Medellín, Colombia, el enfoque del 'Urbanismo Social' buscó no sólo tejer la ciudad física, sino también, socialmente. Acciones concretas en un barrio llamado 'Comuna Popular' suscitaron la mejora de la seguridad por operaciones de gobernanza nodal, cohesión social e intervención de un espacio público inclusivo y poroso.

La implantación de grandes obras de infraestructura, específicamente de transporte público y de educación, son claras muestras de ello. El Metrocable, o Línea K del Metro fue la acción más contundente de acceso del Estado al barrio y se consideró como el pago de la deuda social y el derrumbamiento de las barreras políticas, sociales y económicas. Además se percibe como detonante de las siguientes dinámicas: el rescate de la institucionalidad, la creación de decenas de nuevos negocios comerciales, la accesibilidad para personas con movilidad reducida, la reducción de los homicidios (Ver 'Popular' en Figura 8), la reducción de la limitación territorial y el incremento del valor del suelo. "... Las intervenciones en el sector han buscado dar solución o, al menos, mitigar los conflictos presentes en el territorio, rompiendo físicamente con una frontera territorial impresa por la violencia" (Ballesteros, 2010). 


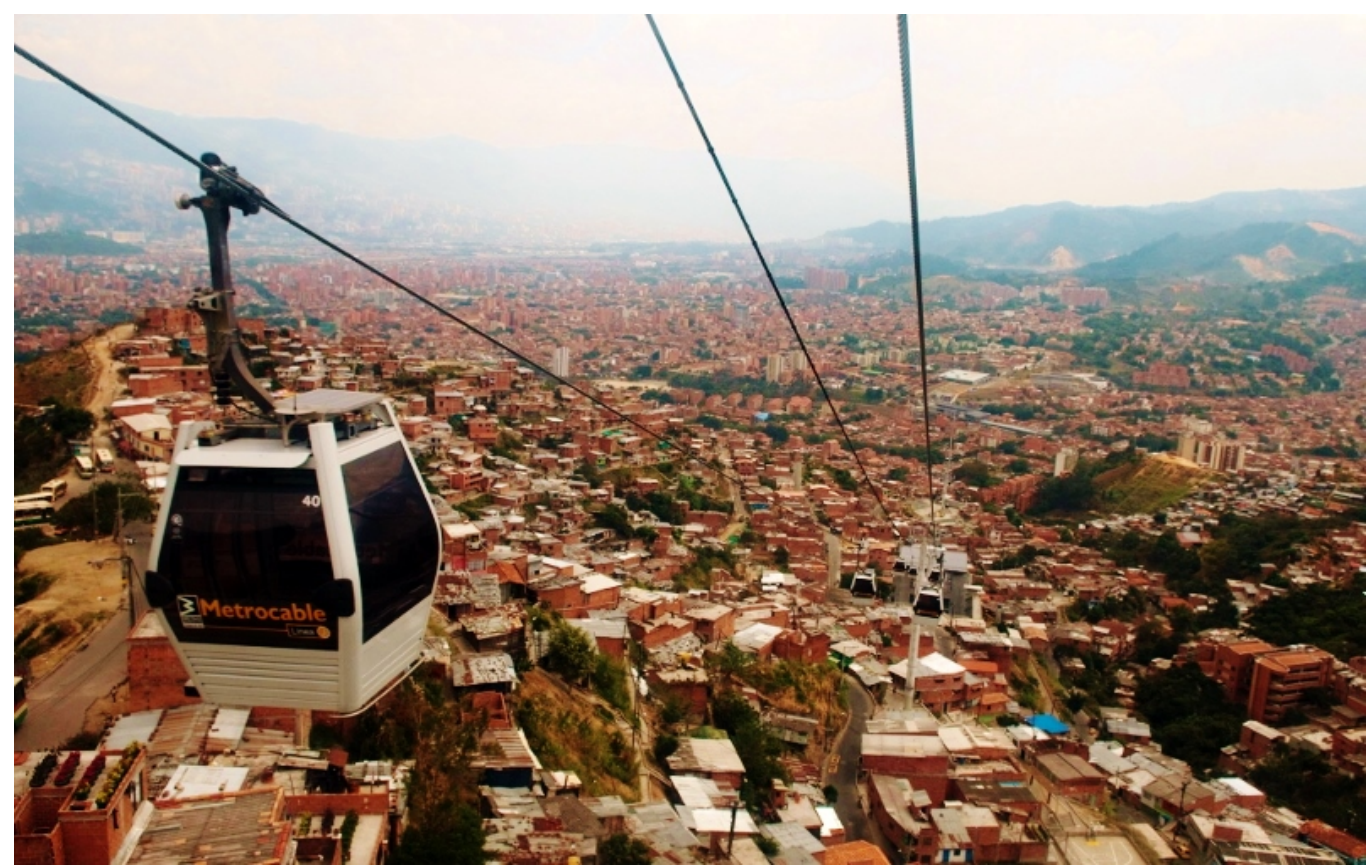

Figura 7. Comuna Popular y Metrocable en Medellín, Colombia

Fuente: Municipio de Medellín, 2015. Extraída el 16 de noviembre de 2015 del sitio web Architecture In Delovelopment: http://architectureindevelopment.org/news.php?id=49

Otro de los hechos de reterritorialización (Ballesteros, 2010) fue la construcción del Parque Biblioteca España, la cual significó otro gesto humanizador del estado hacia la Comuna, imprimiéndole un carácter simbólico y haciendo de ella un sitio de interés para la ciudad. Después del Metrocable y el Parque Biblioteca España, la Comuna Popular ya no era un sitio recóndito, olvidado e ingobernable, era un sitio en donde había lugar para la vida.

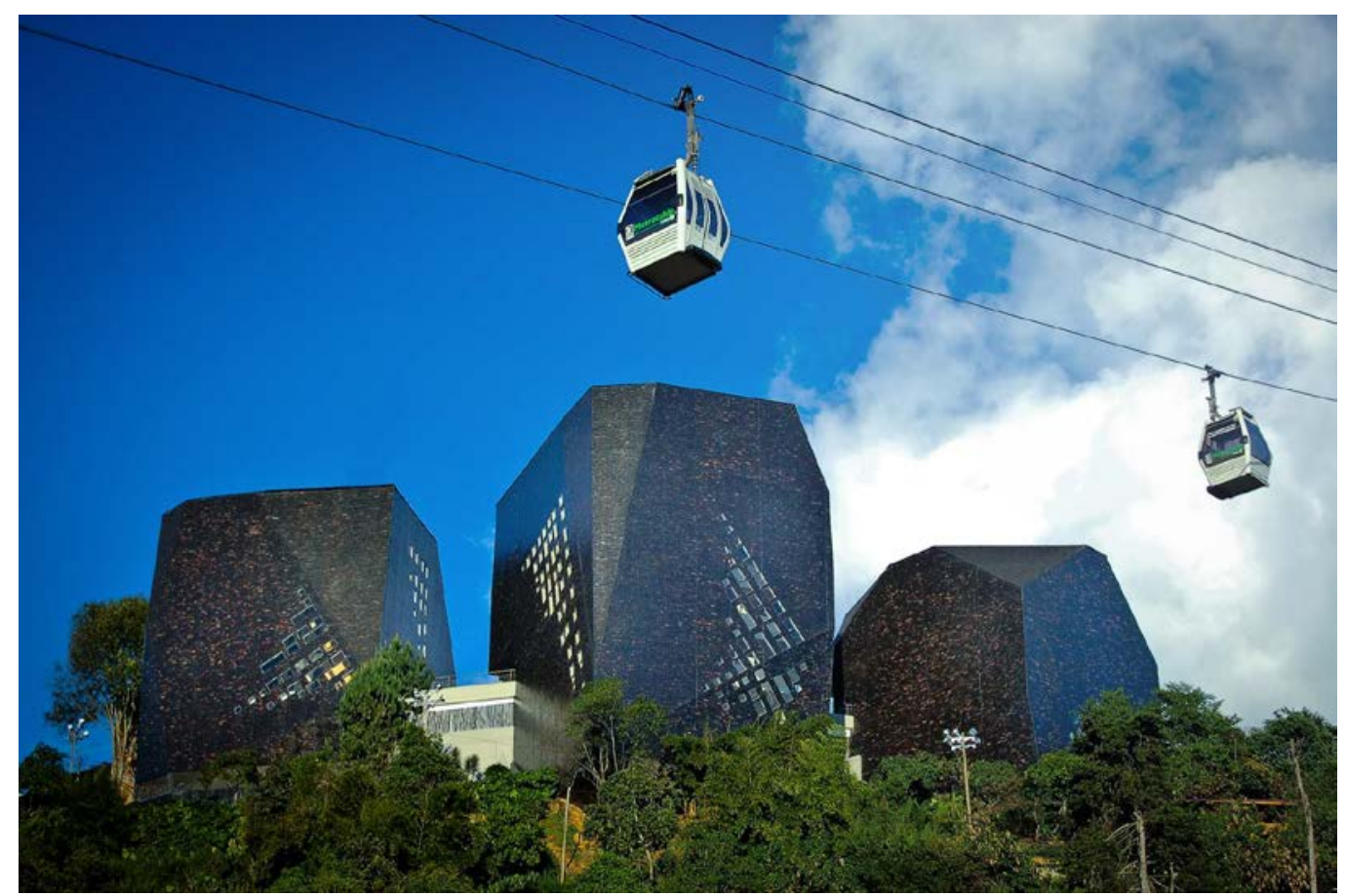

Figura 8. Biblioteca España y Metrocable en Medellín, Colombia

Fuente: Municipio de Medellín, 2015. Extraída el 16 de noviembre de 2015 del sitio web Architecture In Delovelopment: http://architectureindevelopment.org/news.php?id=49

El Urbanismo Social aquí se hace tangible mediante el Programa Integral de Mejoramiento de Barrios Subnormales en Medellín -PRIMED y este a su vez mediante Proyecto Urbano Integral -PUI de la Zona Nororiental. Con una inversión superior a \$200 USD (\$436'000.000.000 COP) el PUI ha dejado 125,000m2 de espacio público generado o mejorado, 18 nuevos parques, un Centro de Desarrollo Económico Zonal 
(CEDEZO), 4 puentes peatonales y 8 pasos peatonales, 11 ferias con microempresarios de la zona y 25 eventos comunitarios orientados a la promoción de la convivencia pacífica con más de 300,000 participantes (UN Habitat, 2011).

Aparte del incremento de la legitimidad y de la confianza de la comunidad hacia lo público y hacia su ciudad, los principales impactos reseñables de esta intervención los podemos apreciar primero en la significativa reducción de homicidios en un $79 \%$, el incremento del 300\% en el sector comercial y en el incremento registrado en el Índice de Calidad de Vida $-\mathrm{ICV}^{4}$ desarrollado por la Universidad de Antioquia -en 1997 registraba 63,58; en 2004, 73,47; en 2007, 77,56 y en 2009, 74,8- (ver 'Popular' en Figura 10).

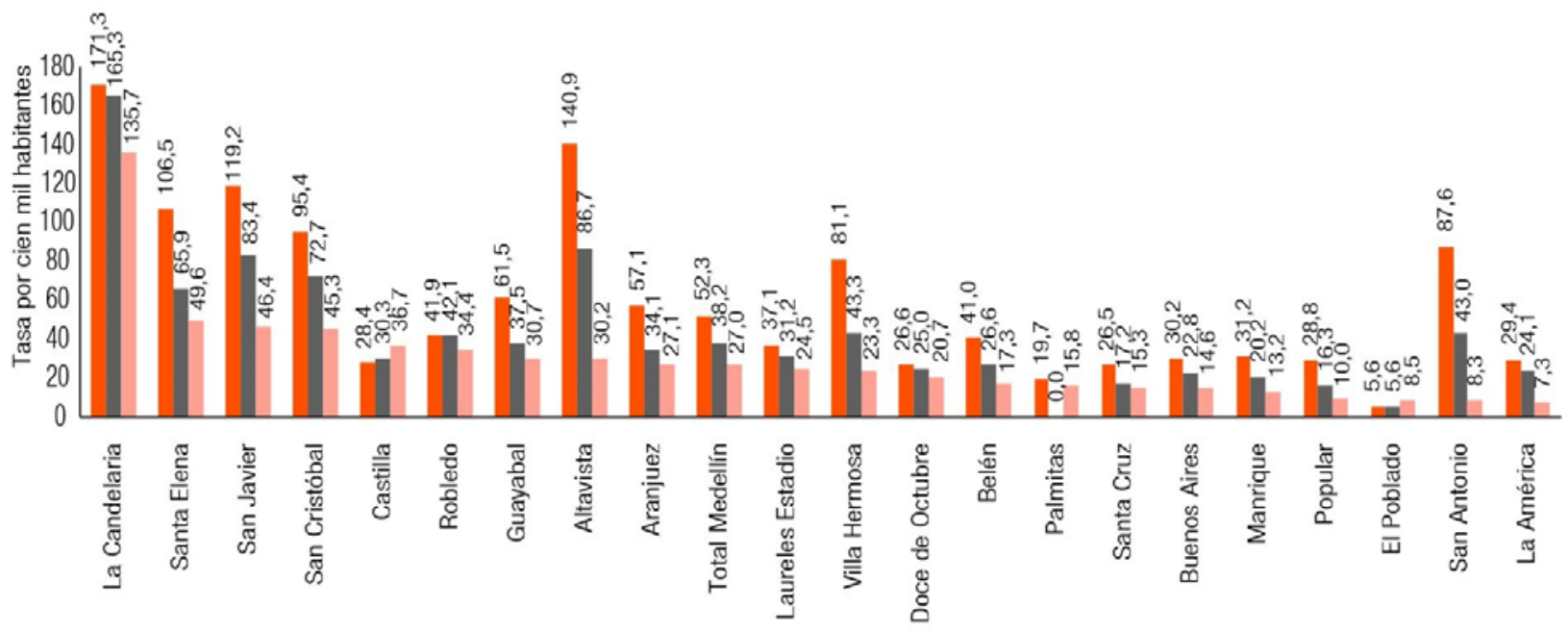

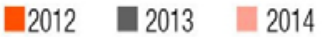

Figura 9. Tasa de homicidios por comuna 2012-2014.

Fuente: Secretaría de Seguridad de Medellín, con datos del DANE. Extraída de: 'Informe de Calidad de Vida Medellín 2014, Seguridad Ciudadana'

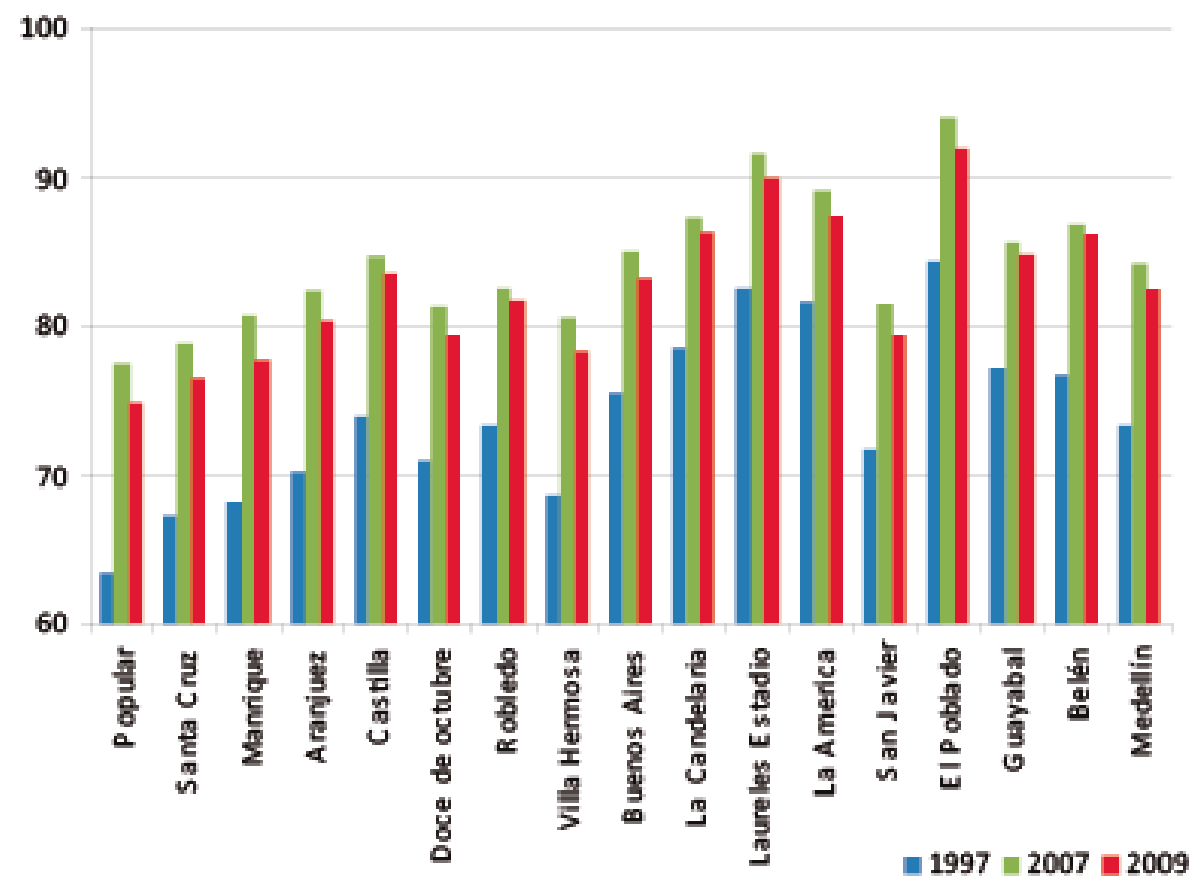

Figura 10. Calidad de vida por comuna 1997, 2997 y 2009.

Fuente: Secretaría del Medio Ambiente de Medellín. Extraída de: 'Plan Ambiental Municipal - PAM: 2012 - 2019, Hacia una ciudad sostenible'

\footnotetext{
4 "El Índice de Calidad de Vida combina en una sola medida las variables de potencial de acceso a bienes físicos, entre éstas, variables que miden capital físico, que toma como indicador las características de la vivienda, variables de infraestructura a través de acceso a servicios básicos de la vivienda, variables de capital humano medido por las características de educación y variables de capital social básico medido por la composición de la familia" (Alcaldía de Medellín, 2011).
} 


\section{CONCLUSIONES}

La seguridad urbana es un valor. Es quizás invisible a los ojos, pero que determina en gran medida la vida de la ciudad, la acción pública en el espacio colectivo y como tal cohesionador y promotor de convivencia. El ponerla en valor implica construir una ciudad libre de fronteras y dispuesta a todos los grupos sociales que confluyan en un espacio público de calidad.

Entender pues el espacio público de la ciudad con contenido, es decir, con gente en él, y vincularlo además al concepto de seguridad, implica pensar en las acciones urbanísticas dadoras de gente al espacio. Aquí la porosidad, la integración y la mezcla urbanas son sólo una aproximación enmarcadas en el concepto madre de 'Fronteras Blandas', que aunque tiene un marcado carácter físico, pondera también las acciones paralelas de gobernanza y gestión social. Es decir, la búsqueda de la ciudad segura no sólo pasa por el espacio público blando, sino también por la ciudad gobernada nodalmente y cohesionada socialmente. Pasa por la urbanidad.

Las Fronteras Blandas son sólo un principio para abordar un proyecto urbano que busque dar vida continuada al espacio, y por consiguiente, seguridad; que busque un regreso a la ciudad pública, a una ciudad blanda y de todos.

\section{FUENTES BIBLIOGRÁFICAS}

ALCALDÍA DE MEDELLín. (2011). Plan Ambiental Municipal - PAM: 2012 - 2019, Hacia una ciudad sostenible. Medellín: Alcaldía de Medellín, Secretaría del Medio Ambiente.

AYUNTAMIENTO DE MADRID. (2007). Ciudades, Urbanismo y Seguridad. Madrid: Ayuntamiento de Madrid, Área de Gobierno de Seguridad y Servicios a La Comunidad, Coordinación General de Seguridad.

BALLESTEROS TORO, J. I. et al. (2010). Santo Domingo Savio: un territorio reterritorializado. Revista Territorios (Bogotá), №22, pp. 87-110.

BENJAMIN, Walter. (2011). Denkbilder. Epifanías en viajes. Buenos Aires: El Cuenco de Plata.

BRANTINGHAM, P. J. Y BRANTINGHAM P. L. (1981). Environmental criminology. New York: Sage Publications.

CARRIÓN, F. (2008). Violencia urbana, un asunto de ciudad. Revista Eure (Quito), Vol. XXXIV, n¹03, pp. 111-130.

CENTRE INTERNATIONAL POUR LA PRÉVENTION DE LA CRIMINALITÉ (CIPC). (2013). L'approche territoriale dans la mise en oeuvre de stratégies de prévention de la délinquance: étude exploratoire d'expériences dans des pays occidentaux. Montreal: Février.

CIOCOLETTO, A. y Col-lectiu Punt 6 (2014). Espacios para la vida cotidiana: Auditoría de Calidad Urbana con perspectiva de Género. Barcelona: Comanegra.

DAMMERT, L. (2007). Ciudad y seguridad: más allá de la dicotomía entre prevención y control. Madrid: Ayuntamiento de Madrid, Área de Gobierno de Seguridad y Servicios a La Comunidad Coordinación General de Seguridad.

DAMMERT, L. (2007b). Seguridad pública en América Latina: ¿qué pueden hacer los gobiernos locales? Revista Nueva Sociedad (Madrid), N²12, pp. 67-81.

DÍAZ, I. y HONORATO, C. (2011). El urbanismo del miedo y la sociedad contemporánea. Revista Viento Sur (Madrid), N¹16, pp. 58-67.

GIRALDO RAMÍREZ, J. (2010). Seguridad en Medellín: el éxito, sus explicaciones, limitaciones y fragilidades. Medellín: Centro de Análisis Político, Universidad EAFIT.

JACOBS, J. (1961). The Death and Life of Great American Cities. New York: Random House. 
MEDELLíN CÓMO VAMOS. Informe de Calidad de Vida Medellín 2014, Seguridad Ciudadana. Disponible en: http://www.medellincomovamos.org/seguridad-y-convivencia

MEDINA ARIZA, J. (2011). Políticas y estrategias de prevención del delito y seguridad ciudadana. Madrid: EDISOFER S.L.

MORENO VALENCIA, J.E. et al. (2011). Boletín 2010 Seguridad y Convivencia en Medellín, Sistema de Información para la Seguridad y la Convivencia - SISC. Medellín: Secretaría de Gobierno de Medellín.

NEWMAN, O. (1972). Defensible Space: Crime Prevention through Urban Design. New York: MacMillan.

NEWMAN, O. (1996). Creating Defensible Space, Institute for Community Design Analysis. Washington, DC: Department of Housing and Urban Development Office of Policy Development and Research.

SANZ, F. (2008). La seguridad en las ciudades: el nuevo enfoque de la geoprevención. Revista Electrónica de Geografía y Ciencias Sociales (Barcelona), Vol. XII, núm. 270 (14).

SHEARING, C. y WOOD, J. (2011). De la práctica del gobierno estatal a la práctica del gobierno nodal. En, Pensar la seguridad, Serie Criminología. Barcelona: GEDISA.

SOOMEREN, P (2011). Prevención de la delincuencia mediante el diseño ambiental y mediante el espacio urbano y arquitectónico. Revista Catalana de Seguridad Pública (Barcelona), №9, pp. 11-37.

UN HABITAT. (2011). Building Urban Safety through Slum Upgrading. Nairobi: United Nations Human Settlements Program.

\section{FUENTES ELECTRÓNICAS}

MIZRAHI, D. (2015). Las 10 ciudades más seguras y las 10 más peligrosas del mundo. Obtenido el 07 de junio de 2015, de http://www.infobae.com/2014/08/30/1591267-las-10-ciudades-mas-seguras-y-las-10-maspeligrosas-del-mundo 